\title{
The effect of feeding on the motility of the stomach and small intestine in the pig
}

\author{
BY Y. RUCKEBUSCH AND L. BUENO \\ Laboratoire de Physiologie-Pharmacodynamie, \\ Ecole Nationale Vétérinaire, 3 1076 Toulouse Cédex, France \\ (Received 14 October 1975 - Accepted 5 November 1975)
}

\begin{abstract}
I. Electromyographical studies were made on the motility of the stomach and small intestine of five pigs when given a standard diet either $a d$ lib., or as one or two meals/d. Recordings were made from electrodes placed chronically on the antrum, the duodenum and the jejuno-ileum, and a continuous $24 \mathrm{~h}$ recording was made every $2 \mathrm{~d}$ for a period of 4 weeks. A simple ' $T$ '-shaped cannula was positioned in the proximal duodenum in two of the pigs.

2. The basic pattern of activity of the small intestine was grouped in phases of irregular and regular activity characteristic of the myoelectric complex. This pattern recurred about eighteen times/d in fasting pigs, or in animals fed $a d l i b$. and so eating frequent but small meals. When a myoelectric complex on the duodenum reached its regular 'spiking' phase, antral activity and passage of digesta ceased completely for a period (5-I5 min) which varied according to the time elasped since the last meal.

3. In animals receiving one meal/d a postprandial pattern of activity lasted about $6 \mathrm{~h}$. The proximal part of the intestine showed continuous activity with vigorous isolated or peristaltic spike bursts. The average number of myoelectric complexes was thirteen/d. When receiving two meals/d the postprandial pattern lasted for only 2-3 h, and approximately sixteen myoelectric complexes/d were recorded.

4. It is concluded that the extent of disruption of the basic intestinal motility pattern depends on the amount of food consumed per meal and subsequent release of nutrients.
\end{abstract}

The motor activity of the digestive tract is similar in all species, but feeding behaviour differs widely. Occasional meals of high energy content are sufficient to satisfy the energy requirements of carnivores, and large amounts of bulky material, necessitating continuous activity of the gastrointestinal musculature, are the rule for herbivores. Omnivores occupy an intermediate position between these two extremes (Hill, 1970).

A considerable amount of information on gut motility obtained by electromyographic techniques exists in the literature for both carnivores and herbivores, and indicates marked differences between the two groups. Fasting dogs show relative inactivity of the small intestine, which is interrupted each 90-120 $\mathrm{min}$ by a phase of irregular and then regular spiking activity called the myoelectric complex (Szurszewski, 1969). After feeding, continuous spiking activity lasting about $10-12 \mathrm{~h}$ disrupts this pattern. Sheep and cattle given a diet of hay have a basic pattern of myoelectric complexes which is always present regardless of the period of feeding (Ruckebusch \& Buéno, I973).

In the pig the stomach usually does not empty completely (Rérat \& Lougnon, I963) and gastric emptying after feeding has been studied in detail (Laplace \& Thomassone, 1970). Only a relatively low flow of digesta $(200-250 \mathrm{ml} / \mathrm{h})$ persists after fasting (Noakes, Hill, Freeman \& Annison, 1967) although recent long-term mechanical 
recordings from the antrum indicate an almost continuous activity interrupted regularly by brief quiescent phases (Plonait, 1974).

A detailed electromyographic study related to different feeding patterns was undertaken in an attempt to correlate the above diverse results existing for this species. In these experiments the motility of the antrum and small intestine was recorded in pigs fed ad lib., and when receiving one or two meals/d. The passage of digesta was compared with the patterns of electrical activity.

\section{MATERIALS AND METHODS}

\section{Animals}

Five female Pitman-Moore minipigs, 3-4 years old, and weighing approximately $60-70 \mathrm{~kg}$, were used. Under thiopentone anaesthesia stainless-steel electrodes were implanted on the antrum and the small intestine (Ruckebusch, 1970). The electrodes were fixed in groups of three, 2 mm apart. In pigs $\mathrm{I}_{2} 2$ and 3 , eight such groups were implanted as follows: three on the antrum, I0O, 20 and $10 \mathrm{~mm}$ anterior to the pylorus: one on the duodenal bulb; two on the duodenum, 180 and $980 \mathrm{~mm}$ posterior to the pylorus; two on the proximal jejunum $\mathrm{I} m$ apart, i.e. approximately $\mathrm{I} \cdot 9^{8}$ and $2.98 \mathrm{~m}$ posterior to the pylorus. In pigs 4 and 5 , five additional groups were implanted at $2 \mathrm{~m}$ intervals along the jejuno-ileum. In these pigs a strain-gauge was fixed on the antrum, oriented transversely, between the first two electrode sites, and a ' $T$ '-shaped cannula was placed in the duodenum, $180 \mathrm{~mm}$ posterior to the pylorus.

The animals were placed in modified metabolism cages which allowed free movement but ensured sufficient restraint for long-term recording. The room temperature was $18-20^{\circ}$, with artificial lighting for $\mathrm{I} 4 \mathrm{~h} / \mathrm{d}$. From to $\mathrm{d}$ after surgery, electrical activity was recorded for periods of $24 \mathrm{~h}$ every $2 \mathrm{~d}$ for 4 weeks, using a twelve-channel, 'direct writing' polygraph (Reega XII; Alvar Electronic, 93-Montreuil, France) at a recording speed of $2.5 \mathrm{~mm} / \mathrm{s}$. Concurrent summation of the electrical activity from three electrode sites at $20 \mathrm{~s}$ intervals was obtained by a triple linear integrator circuit (Latour, 1973) connected to a potentiometric recorder.

\section{Diets}

Initially, the pigs received a diet of $(\mathrm{g} / \mathrm{kg})$ barley 700 , wheatings I $_{5}^{\circ}$ and fish meal 150, with tap-water ad lib. A photocell was used to record periods of feeding. A mean intake of $30-40 \mathrm{~g}$ dry matter $/ \mathrm{kg}$ live weight per $\mathrm{d}$ was established and was used as a basic ration during the experiment. Meals were prepared as a $\mathrm{i}: 2$ mixture of food and tap-water. In pigs 1,2 and 3 , after an initial fast of $24 \mathrm{~h}$, the whole day's ration was given as a single meal at 08.00 hours each day for I week. Then after a fast of $24 \mathrm{~h}$, the day's ration was divided between two meals at 08.00 and 20.00 hours daily for a period of I week. Then the pigs were again supplied with the ration and tap-water ad lib. Pigs 4 and 5 were maintained on one meal/d throughout the experiment. The passage of digesta was estimated by opening the ' $T$ '-shaped cannula, and collecting the outflow at $2 \mathrm{~min}$ intervals for periods of $\mathrm{I}-2 \mathrm{~h}$. These contents were not returned to the intestine. 

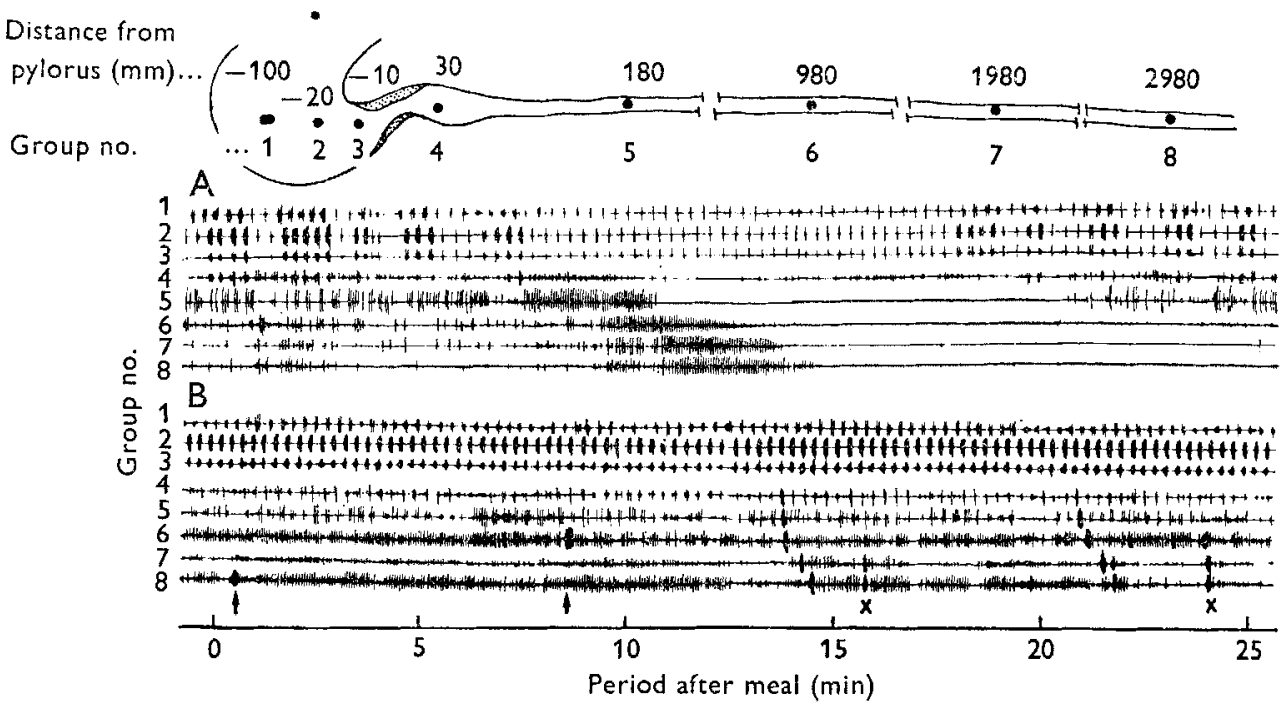

Fig. I. Electromyogram from eight groups of electrodes (O) positioned on the antrum and small intestine in the pig. (A) Basic pattern showing grouped spiking activity on the antrum and its quiescence during the passage of a myoelectric complex along the duodenum. (B) Postprandial pattern about $60 \mathrm{~min}$ after a meal in a pig receiving one meal $/ \mathrm{d}$. Continuous activity on the antrum, and an isolated burst of intense activity $(\boldsymbol{A})$, and two peristaltic sequences on the small intestine $(x)$ can be seen simultaneously $\mathbf{I} m$ apart.

\section{RESULTS}

\section{Basic motility patterns}

The pattern of electrical activity recorded from the antrum and proximal part of the small intestine before the morning meal, or when the animal was fasted for $24 \mathrm{~h}$ (Fig. I A), showed the following characteristics. Slow waves recurred at a frequency of $3.3 \mathrm{cycles} / \mathrm{min}$ on the antrum and of $17 \mathrm{cycles} / \mathrm{min}$ on the duodenum. They constituted the basic electrical rhythm (BER) controlling the frequency of contractions. Bursts of spike potentials which cause actual contractions were periodically superimposed on three or four consecutive antral slow waves, giving a pattern of activity occupying about $50 \%$ of the time. About one-third of the intestinal slow waves were superimposed with randomly occurring short spike bursts. This phase, termed irregular spiking activity, lasted about $5^{\circ} \mathrm{min}$ and was followed by a regular spiking phase of 5 min during which strong spike bursts occurred at the same rate as the slow waves.

This pattern of spiking occupied $55^{-60} \mathrm{~min}$ and alternated with periods of quiescence of 10-20 min; it was recorded at successive electrode sites along the small intestine and represented the migrating myoelectric complex (MMC). The corresponding integrated record indicated that the spiking activity occupied from 50 to $70 \%$ of the total recording time, and that the MMC recurred at intervals of $75-80 \mathrm{~min}$. The integrated antral record showed irregular peaks due to the grouped spike bursts, and ceased completely for $10 \mathrm{~min}$ when the regular spiking phase developed on the proximal duodenum (Fig. $2 \mathrm{~A}$ ). 

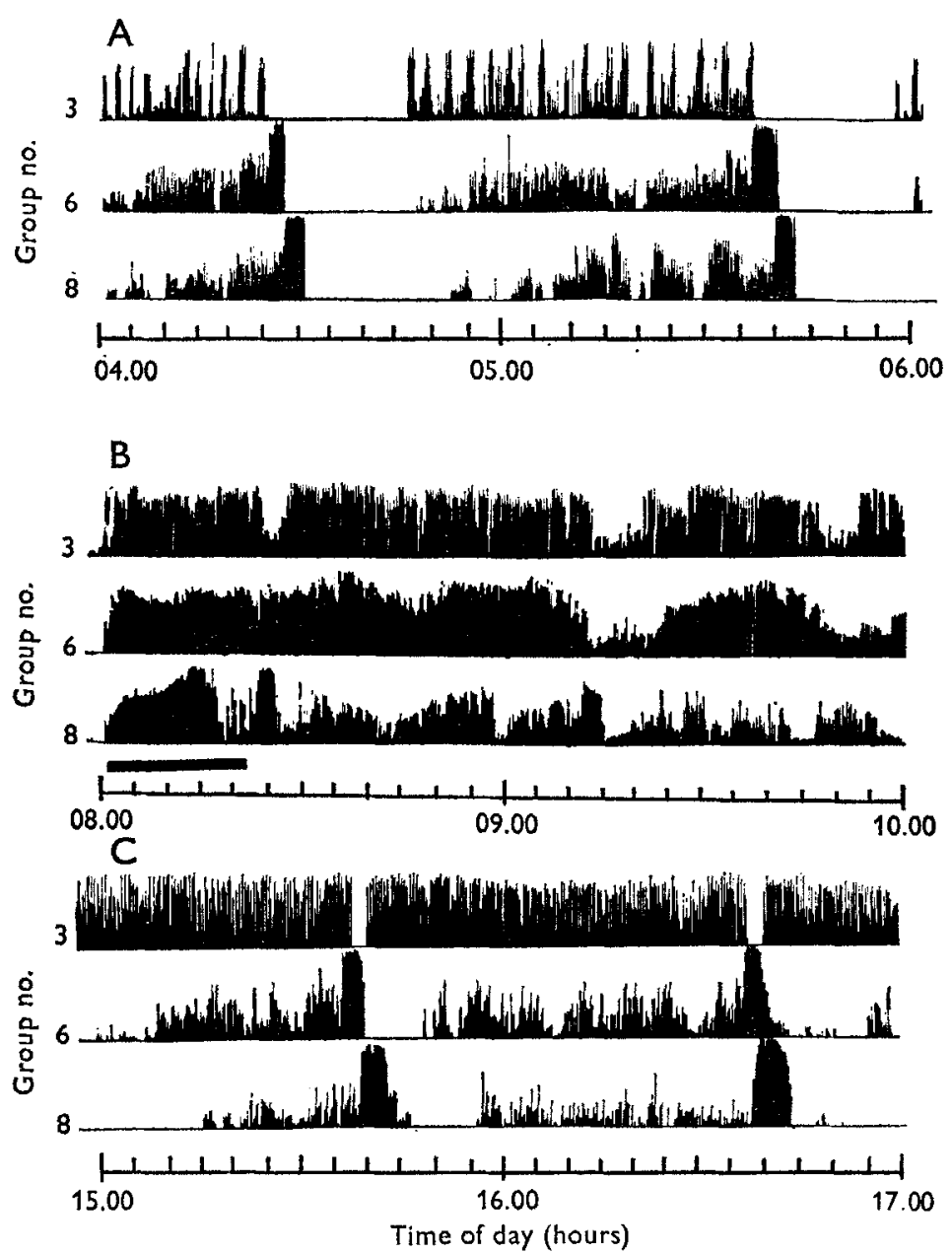

Fig. 2. Summation of the electrical spike activity during $20 \mathrm{~s}$ periods from three sets of electrodes placed on the antrum (electrode site 3 in Fig. 1 ), and $2 \mathrm{~m}$ apart on the proximal jejunum (electrode sites 6 and 8 in Fig. 1 ), for periods of $2 \mathrm{~h}$ in a pig receiving one meal/d. (A) a $3 \mathrm{~h}$ period before feeding; (B) during and after feeding; (C) $7 \mathrm{~h}$ later. $\mathrm{a}$, Period of feeding.

\section{Postprandial patterns}

When pigs were receiving one large meal/d the pattern of electrical activity was characterized by almost continuous spiking activity on both antrum and small intestine, lasting $6 \mathrm{~h}$. In four of the five pigs, the antral slow-wave frequency was increased by $\mathrm{I}_{5}-20 \%$. In all pigs strong spike bursts were superimposed on each slow wave, some of them being propagated through the pylorus. On the duodenum the MMC was disrupted by continuous activity, the spike bursts, irregular in amplitude and duration, occurring for $90 \%$ of the recording time. In addition occasional strong spike bursts were seen simultaneously at one or two electrode sites, and others, isolated or grouped, were propagated from the duodenal bulb at a high velocity (50-80 mm/s) over a distance of $2-3 \mathrm{~m}$ (Fig. I B). This probably represented peri- 
A



Fig. 3. The sequence of electrical activity over a period of $24 \mathrm{~h}$, from one set of electrodes on the proximal jejunum of pigs (site 7 in Fig. I). The pigs: (A) were fasted for $24 \mathrm{~h}$, (B) received one meal/d, (C) received two meals/d, or (D) received food ad lib. $\square$, Period of feeding; $\square$, irregular spiking phases; |, regular spiking phases; postprandial activity.

staltic activity, and in two of the five pigs this was followed occasionally by reverse contractions over a distance of $\mathrm{I}-3 \mathrm{~m}$. When reverse contractions reached the pylorus, antral slow waves and spike bursts disappeared altogether for $30-60 \mathrm{~s}$. The activity of the entire length of the small intestine, including the ileum, was intense (Fig. 2 B) for about $6 \mathrm{~h}$ after feeding, after which a progressive reduction occurred. This involved a reduction of the spike bursts on the antrum and the disappearance of strong spike bursts, either isolated or propagated, on the proximal part of the small intestine. In all instances, often as rapidly as $3 \mathrm{~h}$ after feeding, the regular spiking phase of the MMC reappeared during the period of intense activity, and was accompanied by cessation of antral spiking activity for about $5 \mathrm{~min}$ (Fig. ${ }_{2} \mathrm{C}$ ). The average number of MMC in pigs fed once daily was thirteen/d.

When the ration was supplied in two meals/d, the postprandial pattern lasted $3 \mathrm{~h}$ after the morning meal and $2 \mathrm{~h}$ after the evening meal. The jejuno-ileal activity also increased, but to a lesser extent than on a regimen of one meal/d. As before, the occurrence of a regular spiking phase was accompanied by disappearance of spike bursts on the antrum. The average number of MMC was sixteen/d. When given free access to food the animal indulged in ten to fourteen feeding periods/d, almost all of them during the day-time. In this situation the postprandial pattern concerned only the proximal part of the small intestine, was unable to disrupt the MMC completely, and faded out in less than 20 min (Fig. 3). The number of MMC (eighteen/d) was almost equal to that found when the animal was fasted for $24 \mathrm{~h}$ (Table $\mathrm{I}$ ). 
Table I. Influence of feeding pattern (fasted for $24 h$, fed ad lib., or given one or two meals/d) on the number of intestinal myoelectric complexes/d recorded in five pigs*

(Mean values and standard deviations for three $24 \mathrm{~h}$ determinations)

\begin{tabular}{|c|c|c|c|c|c|c|c|c|}
\hline \multirow{2}{*}{$\begin{array}{l}\text { Pig } \\
\text { no. }\end{array}$} & \multicolumn{2}{|c|}{ Fasted } & \multicolumn{2}{|c|}{ Fed ad lib. } & \multicolumn{2}{|c|}{$\begin{array}{c}\text { Given } \\
\text { one meal/d }\end{array}$} & \multicolumn{2}{|c|}{$\begin{array}{c}\text { Given } \\
\text { two meals/d }\end{array}$} \\
\hline & Mean & SD & Mean & SD & Mean & SD & Mean & SD \\
\hline I & $18 \cdot I$ & 0.3 & $18 \cdot 3$ & 0.9 & $12 \cdot 9$ & 0.9 & 15.6 & 0.7 \\
\hline 2 & 18.0 & 0.9 & $17 \cdot 6$ & 0.6 & I $2 \cdot 8$ & 0.9 & $r_{4} \cdot 2$ & 0.8 \\
\hline 3 & r8.I & 0.6 & 18.2 & 0.6 & 13.4 & 0.6 & $16 \cdot 1$ & 0.6 \\
\hline 4 & & & $I 7^{\prime I}$ & $I \cdot I$ & 10.4 & 0.9 & & \\
\hline 5 & & & $16 \cdot 3$ & 0.9 & I3.O & 0.9 & & \\
\hline
\end{tabular}

* The electrode site selected for compilation was that situated $980 \mathrm{~mm}$ from the pylorus. For details of experimental procedure, see p. 398 .

Table 2. Effect of feeding on the flow of intestinal contents collected from a duodenal ' $T$ '-shaped cannula, and patterns of intestinal motility in pigs 4 and 5 receiving one meal/d*

(Mean values and standard deviations; no. of measurements in parentheses)

\begin{tabular}{|c|c|c|c|c|c|c|c|}
\hline \multicolumn{8}{|c|}{ Postprandial pattern } \\
\hline \multirow[b]{2}{*}{$\begin{array}{l}\text { Period after } \\
\text { feeding }(h)\end{array}$} & \multirow[b]{2}{*}{$\begin{array}{l}\text { Pig } \\
\text { no. }\end{array}$} & \multicolumn{2}{|c|}{$\begin{array}{c}\text { Digesta } \\
\text { collected } \\
(\mathrm{ml} / \mathrm{h})\end{array}$} & \multicolumn{2}{|c|}{$\begin{array}{c}\text { Antral slow waves } \\
\text { with spike bursts } \\
(\%)\end{array}$} & \multirow{2}{*}{\multicolumn{2}{|c|}{$\begin{array}{l}\text { No. of propagated } \\
\text { isolated bursts } \\
\text { (range/d) }\end{array}$}} \\
\hline & & Mean & $\varkappa_{\mathrm{SD}}$ & Mean & $\overbrace{\mathrm{SD}}$ & & \\
\hline $\begin{array}{l}2-3 \\
4-5\end{array}$ & $\begin{array}{l}4 \\
4 \\
5\end{array}$ & $\begin{array}{l}310 \\
210 \\
197\end{array}$ & $\begin{array}{l}57(3) \\
30(4) \\
68(3)\end{array}$ & $\begin{array}{l}94 \\
75 \\
79\end{array}$ & $\begin{array}{l}3 \\
6 \\
6\end{array}$ & $\begin{array}{r}10-1 \\
4-8 \\
4-7\end{array}$ & \\
\hline \multicolumn{8}{|c|}{ Basic pattern } \\
\hline & & \multicolumn{2}{|c|}{$\begin{array}{l}\text { Digesta } \\
\text { collected } \\
(\mathrm{ml} / \mathrm{h})\end{array}$} & \multicolumn{2}{|c|}{$\begin{array}{l}\text { Duration of } \\
\text { antral inactivity } \\
\text { (min) }\end{array}$} & \multicolumn{2}{|c|}{$\begin{array}{l}\text { Flow during the } \\
\text { irregular spiking phase } \\
\text { (\% total flow) }\end{array}$} \\
\hline feeding (h) & no. & Mean & $\mathrm{SD}$ & Mean & SD & Mean & $\mathrm{SD}$ \\
\hline $8-10$ & $\begin{array}{l}4 \\
5\end{array}$ & $\begin{array}{l}140 \\
160\end{array}$ & $\begin{array}{l}20(4) \\
17(3)\end{array}$ & $\begin{array}{l}4 \\
3\end{array}$ & $\begin{array}{l}3 \\
3\end{array}$ & $\begin{array}{l}89 \\
85\end{array}$ & $\begin{array}{r}6 \\
\text { II }\end{array}$ \\
\hline $18-20$ & $\begin{array}{l}4 \\
5\end{array}$ & $\begin{array}{l}\text { I } 30 \\
\text { I } 4 \text { I }\end{array}$ & $\begin{array}{r}17(6) \\
9(7)\end{array}$ & $\begin{array}{r}\text { I } 5 \\
9\end{array}$ & $\begin{array}{l}7 \\
2\end{array}$ & $\begin{array}{l}94 \\
91\end{array}$ & $\begin{array}{l}4 \\
3\end{array}$ \\
\hline
\end{tabular}

\section{Correlation of passage of digesta with antral activity}

Measurement of the rate of flow of digesta through the duodenum by opening the cannula sometimes disturbed the animal, causing it to stand up, and there was a cessation of spiking activity lasting 5-ro min, or some disruption of the MMC. However, each time spike bursts were propagated at high velocity along the duodenum, gushes of $30-40 \mathrm{ml}$ digesta were collected. When regular spiking activity developed on the electrode site near the cannula all flow stopped.

When the pigs remained recumbent or asleep during the opening of the cannula more 
normal changes in digesta flow were found. The highest flow of contents occurred immediately after a meal was taken, and it then decreased progressively (Table 2). Compared with this initial phase, during the period $2-5 \mathrm{~h}$ postprandial, the flow-rate was decreased by $30 \%$, the number of propagated bursts on the duodenum was halved, and the percentage of antral slow waves with spike bursts superimposed was reduced by $15 \%$.

Information obtained from the strain-gauge indicated cessation of antral contractions at regular intervals of $72-80 \mathrm{~min}$. This inactivity lasted about $3-4 \mathrm{~min}$ in the period 8-10 h after feeding, and 9-I $5 \mathrm{~min}$ in the period $18-20 \mathrm{~h}$ after feeding. This concurred with an absence of spiking on the antrum, a regular spiking phase of an MMC propagated along the duodenum, and the absence of duodenal digesta flow. In contrast, the highest digesta flow-rate was recorded towards the end of each irregular spiking phase. The flow-rate remained approximately the same regardless of the time elapsed since feeding, even though there was an increase in the quiescent phase of both antrum and proximal duodenum (Table 2). The alternation of flow and no-flow became increasingly distinct with time.

\section{DISCUSSION}

Summation of the electrical activity at $20 \mathrm{~s}$ intervals provided a condensed view of the alternation of quiescent and spiking phases of the antrum and the small intestine. This type of record indicated clearly the phases of regular spiking activity on the small intestine. By contrast, the measurement of digesta flow by a simple cannula gave only approximate values, since some digesta may have by-passed the cannula, while the failure to return digesta may have affected the flow. Nevertheless it was probably sufficient to indicate the pattern of digesta flow. This technique was preferred to that of a re-entrant cannula, which necessitates transection of the intestine and alters the slow-wave frequency gradient.

The striking feature indicated by the recordings was the almost uninterrupted recurrence of the MMC every 72-80 min on the small intestine, not only in fasted animals but also in those fed ad lib. Thus, in the latter instance, the MMC also represents the main factor in propelling digestive contents along the intestine. Clearly the size of a meal has a marked influence on the way food is propelled along the intestine. The consequences of this on rate of propulsion and the efficiency of intestinal digestion have yet to be defined. Moreover, these differing patterns of intestinal function may be linked to differing patterns of metabolic utilization of the products of digestion, for in dogs and sheep the extent of disruption of the MMC sequence is a reflexion of, and direct response to the secretion of insulin (Ruckebusch \& Fioramonti, 1975).

Results of experiments on sheep have indicated that the transition from irregular to regular spiking activity marks the effective point in the propulsion of digesta (Buéno, Fioramonti \& Ruckebusch, 1975). This may explain the alternation of flow and noflow recorded from the cannula after the postprandial phase of continuous activity had subsided. Absence of antral spiking activity at the point when regular spiking 
developed on the duodenum may also explain the irregularities of postprandial flow described by Laplace \& Thomassone (1970), who used re-entrant cannulas. Their recordings indicate clearly the absence of flow for 6-10 min at hourly intervals. These interruptions probably correspond to the periods of relaxation of the antrum indicated by cessation of spiking activity in our tracings (see Fig. 2 C). The relaxation of the proximal duodenum after the regular spiking phase of the MMC would also contribute to the decreased flow-rate.

The postprandial pattern of continuous spiking activity which developed when the ration was given in one or two meals/d lasted for 6 and $3 \mathrm{~h}$ respectively. Attempts to define a model of gastric emptying have not yet been successful for three main reasons: the very swift evacuation of the liquid phase, the copious secretion of gastric juice which greatly augments the volume of the meal, and the fact that the precise profile of gastric motor activity is unknown. The volume of food and consequent distension of the stomach is the natural stimulus which increases antral motor activity. In dogs the postprandial increase in antral motility is effected by the development of an uninterrupted sequence of vigorous bursts of spikes without change in the BER (Cooke, 1975). Our results suggest the intervention of an additional factor in pigs, the increase in the frequency of the BER of the antrum. A high postprandial frequency of antral slow waves has also been recorded in Large White pigs (Laplace, 1974). The number of spike bursts that are propagated along the duodenum is directly related to the time elapsed since feeding and is also characteristic of a high flow-rate.

Backflow from the duodenum to the stomach is sometimes found in pigs and is presumably responsible for a flow of bile into the stomach. When this occurs, all activity ceases on the antrum for $30-60 \mathrm{~s}$, an effect resembling the profile recorded in dogs during vomiting.

To generalize, one may postulate that in pigs feeding disrupts the basic MMC pattern to varying extents, according to the volume of food ingested at a meal. The motor activity of the pig's antrum and intestine after one large meal resembles that seen in carnivores, and the duration of this effect is approximately halved when two meals/d are given. When pigs are fed $a d$ lib., the motility pattern resembles that seen in ruminants, where the MMC pattern persists regardless of feeding. Going from carnivores to herbivores there is an increasing regularity in the frequency and character of the MMC. When dogs are given food ad lib., the number of meals taken does not exceed seven to eight/d (Ruckebusch, unpublished results) compared with ten to fourteen for pigs and twenty to twenty-five for ruminants. In herbivores, there is also an increased volume of food ingested and subsequently a more regular and continuous delivery of contents of low digestible energy to the duodenum. This comparison suggests that the MMC is the basic motility pattern of the small intestine of all three groups considered, and its intrinsic character is best indicated in those animals with more continuous digestive processes.

Many postprandial factors may be capable of disrupting the basic MMC pattern, for example secretions of the digestive tract, changes in $\mathrm{pH}$ and the release of hormones. Both neural and hormonal mechanisms are probably involved in controlling electrical activity. However, the latter seems more important, at least in sheep (Buéno \& 
Vol. 35

Ruckebusch, I975). In this species, the MMC pattern persisted after both vagotomy and splanchnicectomy, but was altered in alloxan-diabetes and restored by insulin injection.

\section{REFERENCES}

Buéno, L., Fioramonti, J. \& Ruckebusch, Y. (1975). F. Physiol., Lond. 249, 69.

Buéno, L. \& Ruckebusch, Y. (1975). C. r. Séanc. Soc. Biol. 169, 430.

Cooke, A. R. (1975). Gastroenterology 68, 804.

Hill, K. J. (1 970). In Dukes' Physiology of Domestic Animals, p. 402 [M. J. Swanson, editor]. Ithaca and London: Cornell University Press.

Laplace, J. P. (1 974). Recl Méd. vét. Éc. Alfort 150, I21.

Laplace, J. P. \& Thomassone, R. (1970). Annls Zootech. 19, 303.

Latour, A. (1973). Annls Rech. vét. 4, 347.

Noakes, D. E., Hill, K. J., Freeman, C. P. \& Annison, E. F. (1967). Proc. Nutr. Soc. 26, vi.

Plonait, H. (1974). Proc. 3 rd int. Conf. Pig vet. Soc., Lyon Abstr. Lro.

Rérat, A. \& Lougnon, J. (1963). Annls Biol. anim. Biochim. Biophys. 3, 29.

Ruckebusch, Y. (r97o). F. Physiol., Lond. 210, 857.

Ruckebusch, Y. \& Buéno, L. (1973). Br. F. Nutr. 30, 49 r.

Ruckebusch, M. \& Fioramonti, J. (1975). C. r. Séanc. Soc. Biol. 169, 435.

Szurszewski, J. H. (1969). Am. F. Physiol. 217, 1757. 